\title{
Oral anticoagulation to reduce risk of stroke in patients with atrial fibrillation: current and future therapies
}

This article was published in the following Dove Press journal:

Clinical Interventions in Aging

21 January 2013

Number of times this article has been viewed

\author{
Alpesh Amin \\ Hospitalist Program, University of \\ California, Irvine, Orange, CA, USA
}

\begin{abstract}
Atrial fibrillation (AF) is associated with an increased incidence and severity of strokes. The burden of AF-related stroke is expected to increase in parallel with the aging of the population. Oral anticoagulation with warfarin has been the pharmacologic standard for stroke risk reduction in patients with AF. When used with close attention to dosing and monitoring, warfarin is effective prophylactic therapy against thromboembolic stroke. However, it is underused by physicians, in part because of the known risks of adverse events with warfarin. Consequently, many patients with AF live with an avoidably elevated risk of stroke. New options, ie, oral anticoagulants with novel mechanisms of action, have recently been approved to reduce the risk of stroke in AF, and others are in development. These newer agents may address some of the complexities of warfarin use while providing similar or better efficacy and safety.

Keywords: atrial fibrillation, stroke, oral anticoagulants
\end{abstract}

\section{Introduction}

Atrial fibrillation (AF), the most common type of sustained cardiac arrhythmia, is characterized on electrocardiography by rapid, irregular waves that vary in size, form, and timing. ${ }^{1} \mathrm{AF}$ is associated with a high risk of thromboembolism and stroke. The thrombogenic effect is derived from a number of pathologic mechanisms, in particular, flow abnormalities resulting in stasis in the left atrium, as well as abnormal changes in the vessel walls and constituents of the blood. ${ }^{2}$ The frequency of AF, which is estimated to account for $15 \%$ of strokes in the US annually, is projected to more than double by mid-century as more Americans survive to the ninth decade and beyond. ${ }^{3,4}$ The 2.6 million who experienced AF in 2010 will increase to about 12 million by 2050 as the population ages. ${ }^{4}$ The lifetime risk for AF is one in four for Americans older than 40 years. ${ }^{5}$ Approximately $70 \%$ of patients with AF are aged $65-85$ years. ${ }^{6}$

$\mathrm{AF}$ is associated with higher medical costs as well as an increased risk of disability and death from stroke. ${ }^{7}$ Stroke imposes a severe and growing burden on individuals and society, with the incidence of stroke continuing to rise as the population ages and risk-control initiatives are weakly implemented. ${ }^{7}$ The results of numerous studies have shown that therapeutic and behavioral approaches to management of risk factors can bring about marked reductions in most types of cardiovascular disease, including stroke, not only at the population level but also for individual patients at high risk. . $^{7}$ As a leading risk factor for stroke, $\mathrm{AF}$ is an important target for prevention by pharmacologic means.

The annual economic burden of stroke in the US was estimated at \$54 billion in 2010. Direct costs of stroke are on track to grow by $238 \%$ over the 20 -year period up to 2030 , 
a rate much higher than all other categories of cardiovascular disease. ${ }^{8}$ By 2030 , direct costs of stroke will sap $\$ 95.6$ billion from the US annual health care budget, and indirect costs, another $\$ 44.4$ billion. $^{8}$ It should be noted that indirect costs, based largely on productivity, grow more slowly than direct costs, mainly because relatively few older Americans, ie, those in the age group most vulnerable to strokes, are active in the workforce. ${ }^{8}$ It is also noteworthy that the US health care system spends less than $\$ 600$ million a year on preventive care for patients at risk for thrombotic events. ${ }^{9}$

\section{Incidence, prevalence, and risk factors}

The costs and hazards of AF are exacerbated by comorbid conditions that are common in the older population and also increase the risk of stroke. A study of hospitalized Medicare patients found that the presence of AF plus a concomitant cardiovascular diagnosis increased the risk of stroke by $10 \%$ in men and $25 \%$ in women compared with patients who had AF in the absence of coronary artery disease. ${ }^{10}$ The odds of experiencing an AF-related stroke are also influenced by patient characteristics. For example, in the ATRIA (Anticoagulation and Risk Factors in Atrial Fibrillation) study, among patients who did not receive anticoagulant therapies, women had a 1.6-fold higher annual incidence of ischemic stroke and peripheral thromboembolism than men; ${ }^{11}$ however, female gender has inconsistently been found to be a risk factor in other studies. ${ }^{7}$

The risk of stroke increases along with AF as patients grow older, even when no other stroke risk factors are present. ${ }^{12}$ However, generally, the age-related increase in stroke risk is attributable to a higher prevalence of AF-related predisposing conditions, as well as conditions that are associated with increased stroke risk but independent of $\mathrm{AF}^{7}$

The $\mathrm{CHADS}_{2}$ score is a risk assessment scheme widely used to identify patients with AF who are likely to benefit from anticoagulant prophylaxis against stroke. $\mathrm{CHADS}_{2}$ assigns one point each to four of five critical risk factors, ie, congestive heart failure $(\mathrm{C})$, hypertension $(\mathrm{H})$, age $\geq 75$ years $(\mathrm{A})$, and diabetes mellitus (D), and two points to the fifth, ie, previous stroke (S) or transient ischemic attack. ${ }^{13}$

The original $\mathrm{CHADS}_{2}$ had relatively modest predictive value for stroke, especially for patients at intermediate risk. ${ }^{13}$ Therefore, the $\mathrm{CHA}_{2} \mathrm{DS}_{2}$-Vasc scheme was developed to address the deficiencies of $\mathrm{CHADS}_{2}$ by incorporating one point each for additional risk factors, including vascular disease (V: prior myocardial infarction, peripheral arterial disease or aortic plaque) and female gender $\left(\mathrm{S}_{2}\right)$, as well as by stratifying patients into age groups $\left(\mathrm{A}_{2}\right)$ of $65-74$ years (1 point) or $\geq 75$ years ( 2 points). ${ }^{13} \mathrm{CHA}_{2} \mathrm{DS}_{2}$-Vasc has better predictive value for thromboembolism than $\mathrm{CHADS}_{2}$, particularly for patients at lower and intermediate stroke risk levels. When $\mathrm{CHA}_{2} \mathrm{DS}_{2}$-Vasc was compared with $\mathrm{CHADS}_{2}$ in a real-world cohort of $1084 \mathrm{AF}$ patients who did not receive anticoagulation at baseline, the schemes identified $9.2 \%$ and $20.4 \%$ of patients as having low risk (a score of 0 ), respectively. ${ }^{13}$ Thromboembolic events occurred in $0 \%$ of low-risk $\mathrm{CHA}_{2} \mathrm{DS}_{2}$-Vasc patients compared with $1.4 \%$ of low-risk $\mathrm{CHADS}_{2}$ patients. ${ }^{13}$ Thus, $\mathrm{CHA}_{2} \mathrm{DS}_{2}$-Vasc recognizes a higher risk level for many patients considered at low risk according to $\mathrm{CHADS}_{2}$. The advantages of $\mathrm{CHA}_{2} \mathrm{DS}_{2}-$ Vasc must be weighed against its greater complexity as a means for nonspecialists to assess stroke risk. ${ }^{13}$

Framingham Heart Study investigators developed a score to predict the 5-year risk of stroke alone and stroke or death in patients with new onset AF. ${ }^{14}$ Overlapping somewhat with $\mathrm{CHADS}_{2}$ and CHAsDS2-Vasc, the Framingham scheme scores advancing age, female gender, increasing systolic blood pressure, prior stroke/transient ischemic attack, and diabetes, and clinical evaluation also takes account of smoking history. Using the system, the investigators developed risk scores for stroke and stroke or death at the time of warfarin initiation for 705 of 868 patients with new-onset AF and examined event rates in low-risk individuals, as defined by the Framingham risk score and four earlier risk schemes, during a mean follow-up of 4 years. According to the Framingham risk score, $14.3 \%$ of the cohort had a predicted 5-year stroke rate $\leq 7.5 \%$ (average annual rate $\leq 1.5 \%$ ) and $30.6 \%$ had a predicted 5-year stroke rate $\leq 10 \%$ (average annual rate $\leq$ $2.0 \%$ ). Actual stroke rates in these low-risk groups were 1.1 and 1.5 per 100 person-years, respectively. According to the earlier risk schemes, $6.4 \%-17.3 \%$ of patients were classified as low-risk, with actual stroke rates ranging from 0.9 to 2.3 per 100 person-years. The investigators noted that the flexible Framingham score provides for use of different thresholds of risk, which is important when tolerability may vary according to the clinical situation. They suggested that the score, which allows stratification at the time of diagnosis, may be helpful both in counseling patients and in making treatment decisions. ${ }^{14}$

In addition to risk stratification scores that offer a means of identifying patients likely to benefit from anticoagulation, other schemes, which calculate the risk of major hemorrhage during anticoagulant therapy, may add further precision to the selection of medication. HAS-BLED (Hypertension, Abnormal renal/liver function, 
Stroke, Bleeding history/disposition, Labile international normalized ratio [INR], Elderly [ $>65$ years], Drugs/alcohol concomitantly) is one bleeding risk score. ${ }^{15}$ Another is HEMORR $_{2}$ HAGES (Hepatic or renal disease, Ethanol abuse, Malignancy, Older [age $>75$ years], Reduced platelet count or function, Hypertension [uncontrolled], Anemia, Genetic factors, Excessive fall risk, Stroke), based on data from quality improvement organizations in seven states and comprising a registry of 3791 Medicare beneficiaries with AF. ${ }^{16}$ The predictive schemes in current use do not equip physicians to achieve the goal of identifying the restricted but significant group of patients with AF who will experience stroke and thus limiting anticoagulation to such patients. ${ }^{13,15}$ The considerable overlap between risk factors for stroke and bleeding may present a confounding challenge. However, investigators suggest that physicians combine use of a bleeding risk score, such as HEMORR ${ }_{2}$ HAGES, with a clinical prediction rule for stroke, and thus "trade off the risks and benefits" of prescribing anticoagulants versus antiplatelet therapy to select the most appropriate therapies for individual patients. ${ }^{16}$

\section{Anticoagulant therapy}

Anticoagulation is an established therapeutic strategy to reduce the risk of stroke in AF patients. ${ }^{17}$ Anticoagulants are prescribed to mitigate hypercoagulable states and reduce the risk of cardioembolic stroke as well as to prevent or treat postoperative deep vein thrombosis and pulmonary embolism (Table 1). ${ }^{17,18}$

\section{Stroke risk reduction with warfarin}

Physicians and patients alike prefer oral medications because they are convenient to administer outside the hospital setting. ${ }^{18}$ Oral anticoagulants (often warfarin, a vitamin $\mathrm{K}$ epoxide reductase inhibitor, commonly referred to as a vitamin $\mathrm{K}$ antagonist) are recommended for long-term stroke risk reduction in AF patients. A meta-analysis of 29 trials evaluated more than 28,000 elderly patients with nonvalvular AF over a mean follow-up of 1.5 years. ${ }^{19}$ With adjusted-dose warfarin, stroke was reduced by $64 \%$, compared with $22 \%$ for antiplatelet therapy (relative risk reduction 39\%; 95\% confidence interval [CI] 22-52; 12 trials, 12,963 patients). ${ }^{19}$ While the methodology and quality of reporting varied among trials in this analysis, warfarin anticoagulation was substantially more effective than antiplatelet therapy in reducing stroke risk; however, other randomized comparisons, including those for adverse events, were inconclusive. ${ }^{19}$

Despite its acknowledged efficacy over more than half a century, warfarin is associated with a number of challenges that may make clinicians reluctant to prescribe it. Most importantly, the blood concentration must be maintained within a narrow therapeutic window to balance antithrombotic benefit against the risk of bleeding, a process that is complicated by substantial heterogeneity of response..$^{20}$ Between $30 \%$ and $50 \%$ of variability in the response to warfarin is attributable to variants in two genes, $C Y P 2 C 9$ and VKORC $1 .{ }^{20}$ Routine genotyping to determine sensitivity to warfarin is not recommended at present, but the US Food and

Table I Oral agents to reduce the risk of stroke in atrial fibrillation

\begin{tabular}{|c|c|c|c|c|}
\hline Drug & Absolute risk of SSE & Major bleeding & Side effects & US availability \\
\hline Warfarin & - $1.71 \%{ }^{43}$ & $\begin{array}{l}\text { - } 3.57 \%^{43} \\
\text { - } 3.4 \%^{46}\end{array}$ & $\begin{array}{l}\text { - Major or fatal bleeding } \\
\text { - Necrosis of skin and other tissues }\end{array}$ & - Generic \\
\hline $\begin{array}{l}\text { Dabigatran } \\
\text { etexilate }\end{array}$ & $\begin{array}{l}\text { - I.54\% (I I0 mg dose; } P<0.00 \text { I } \\
\text { for noninferiority versus warfarin, } \\
\text { NS for superiority })^{43} \\
\text { - I.I I \% (I50 mg dose; } P<0.00 \text { I } \\
\text { for superiority versus warfarin })^{43}\end{array}$ & $\begin{array}{l}2.87 \%^{43}(P=0.003 \\
\text { versus warfarin) } \\
\text { - } 3.32 \%^{43} \text { ( } P=0.32 \\
\text { versus warfarin) }\end{array}$ & $\begin{array}{l}\text { - Serious and sometimes fatal bleeding, } \\
\text { gastrointestinal bleeding, dyspepsia }{ }^{37}\end{array}$ & $\begin{array}{l}\text { - FDA-approved to } \\
\text { reduce SSE risk in } \\
\text { patients with } \mathrm{NVAF}^{37}\end{array}$ \\
\hline Rivaroxaban & $\begin{array}{l}\text { - ITT analysis: } 2.1 \%(P<0.00 \text { I for } \\
\text { noninferiority, NS for superiority })^{46} \\
\text { - On-treatment analysis: I.7\% } \\
(P<0.00 \text { I for noninferiority } \\
\text { versus warfarin })^{46}\end{array}$ & - $3.6 \%{ }^{46}$ & - Bleeding ${ }^{38}$ & $\begin{array}{l}\text { - FDA-approved to } \\
\text { reduce SSE risk in } \\
\text { patients with NVAF }{ }^{38}\end{array}$ \\
\hline Apixaban & - $\mathrm{N} / \mathrm{A}^{49,50}$ & & - Bleeding & $\begin{array}{l}\text { - FDA approval for } \\
\text { SPAF }\end{array}$ \\
\hline ASA & - Inferior to warfarin & & $\begin{array}{l}\text { - Coagulation abnormalities } \\
\text { - Gastrointestinal side effects }\end{array}$ & - Generic \\
\hline $\begin{array}{l}\text { Clopidogrel } \\
\text { plus ASA }\end{array}$ & - Inferior to warfarin $32,34,35$ & & $\begin{array}{l}\text { As for ASA plus: } \\
\text { - Bleeding } \\
\text { - Thrombotic thrombocytopenic purpura }\end{array}$ & $\begin{array}{l}\text { - Approved by the FDA } \\
\text { for other indications }\end{array}$ \\
\hline
\end{tabular}

Abbreviations: ASA, acetylsalicylic acid; FDA, Food and Drug Administration; ITT, intention-to-treat; PE, pulmonary embolism; SPAF, stroke prevention in atrial fibrillation; SSE, stroke and systemic embolism. 
Drug Administration (FDA) has revised the label, advising clinicians to select one of three initial dose ranges, based on the results of clinical trials, when a patient's CYP2C9/ $V K O R C 1$ genotype is known. ${ }^{20}$ Patients' responses to warfarin are influenced by dietary vitamin $\mathrm{K} .{ }^{21}$ Warfarin also competes with dietary flavonoids. ${ }^{21}$

Tight INR control is necessary if stroke is to be prevented effectively and the risk of bleeding reduced, but tight control is sometimes difficult to achieve with warfarin. In a retrospective study of 488 Medicare patients with a history of AF before hospitalization, only 38\% (117/304) of those eligible for anticoagulation had been prescribed warfarin, and patients admitted with a stroke were likely to be significantly undercoagulated, with INR $<1.5(43.5 \%$ compared with $20.9 \%$ of those without stroke; $P<0.005) .{ }^{22}$ In this sample, $60 \%$ of AF patients who were candidates for anticoagulation were not prescribed warfarin, while those who received warfarin were undertreated according to clinical guidelines. ${ }^{22}$ Conversely, nearly $9 \%$ of the patients on anticoagulation had INR that exceeded the upper limit of the therapeutic range. $^{22}$ In a survey of 309 warfarin-treated patients with AF admitted with stroke to six US tertiary care institutions, $40 \%-70 \%$ had an INR outside the therapeutic range. ${ }^{23}$ The level of anticoagulation is inversely associated with stroke and especially with the risk for intracranial hemorrhage, and stroke risk increases dramatically when the INR is $<2 .{ }^{24}$ Bleeding risk rises when the INR exceeds 3.0, and rises steeply at INR values $>4.0 .^{25}$

\section{Interpreting and applying clinical trial data}

The efficacy of warfarin demonstrated in controlled conditions during clinical trials has not always been translated sufficiently to the real-world conditions of clinical practice. A retrospective analysis of health care claims stratified patients with nonvalvular AF into new-to-warfarin $(\mathrm{n}=4895)$ and non-warfarintreated $(n=7644)$ cohorts. ${ }^{26}$ For warfarin-treated patients, risks for ischemic stroke and thromboembolism were reduced by $22 \%$ (hazards ratio $0.78 ; 95 \%$ CI $0.65-0.93$ ) and $34 \%$ (hazards ratio 0.66 ; 95\% CI $0.59-0.75$ ), respectively, over a follow-up of $\leq 720$ days, with no increase in the risk for hemorrhage. Results were adjusted for age, gender, and other risk factors. The observed reductions for stroke and thromboembolism, while considerable, were lower than others reported in clinical trials, leading the authors to infer that "warfarin was used conservatively and dosed cautiously". ${ }^{26}$

One possible explanation for the gap between evidence and practice is that INR monitoring, provided reliably and consistently in a clinical trial, may not be used optimally in the real-world setting. In a survey of 2587 residents of a longterm care facility in Connecticut, 83 were identified as ideal candidates for stroke prevention with warfarin. ${ }^{27}$ However, only about half the patients received warfarin and their INR values were maintained in the therapeutic range only about half of the time. ${ }^{27} \mathrm{~A}$ record-linkage retrospective study in the United Kingdom of 2223 patients with AF showed that warfarin-treated patients were outside the target INR range one third of the time, and that the quartile with poorest control was out of target range almost three quarters of the time. ${ }^{28}$ Interestingly, time outside target range decreased with duration of INR monitoring, from 52\% in the first 3 months, which corresponds to the initial period of warfarin dose adjustment, to $30 \%$ after 2 years. ${ }^{28}$ Results of a multivariate logistic regression analysis showed that a $10 \%$ increase in time out of range was associated with an increased risk of death $(P<0.001)$ and/or ischemic stroke $(P<0.006)$ and other thromboembolic events $(P<0.001){ }^{28}$

Use of point-of-care INR testing devices and attendance at anticoagulation clinics that provide INR testing as part of coordinated care have been associated with better outcomes from warfarin therapy. ${ }^{29}$ Several studies have indicated a positive cost benefit of anticoagulation clinics versus usual care, as reflected in lower rates of adverse events and recourse to hospital services. ${ }^{29}$ However, costs of coordinated care at anticoagulation clinics vary widely; in a review of 29 studies, the cost of a single INR monitoring test ranged from $\$ 6.19$ to $\$ 145.70$ (2006 US dollars). ${ }^{30}$ Although elderly patients are those most in need of chronic oral anticoagulant therapy, they were often the least likely to receive it, partly because there was until recently a dearth of evidence from controlled clinical trials to support the positive risk-benefit of thromboprophylaxis in the elderly. In the BAFTA (Birmingham Atrial Fibrillation Treatment of the Aged) trial, dose-adjusted warfarin with a target INR of 2.5 was compared with acetylsalicylic acid $75 \mathrm{mg} /$ day in patients aged $>75$ years in the primary care setting. ${ }^{31}$ Warfarin was associated with a significant reduction in the occurrence of fatal or nonfatal disabling stroke (ischemic or hemorrhagic, or significant arterial embolism; odds ratio 0.48 ; 95\% $\mathrm{CI} 0.28-0.80$; number needed to treat, 80 ) with no difference between the warfarin-treated and acetylsalicylic acid-treated groups in the risk of intracerebral hemorrhage and all other major hemorrhages. ${ }^{31}$ These persuasive findings may have contributed to positive changes in clinical management of elderly patients at risk for thrombotic events. 


\section{Antiplatelet therapy to reduce stroke risk in AF}

Numerous studies have demonstrated that acetylsalicylic acid provides only modest stroke prevention compared with the effect achievable when warfarin is administered with meticulous attention to dosing and monitoring. In 2011, the American College of Cardiology/American Heart Association/American Stroke Association updated their joint practice guidelines to suggest that, as an alternative to acetylsalicylic acid monotherapy, acetylsalicylic acid may be combined with the thienopyridine antiplatelet agent, clopidogrel, to prevent stroke in patients who are not candidates for warfarin, whether because of patient preference or the physician's clinical assessment. ${ }^{32}$ The American College of Chest Physicians recommends acetylsalicylic acid monotherapy $75 \mathrm{mg}$ to $325 \mathrm{mg}$ per day in AF patients with a CHADS score of 0 , or combined with clopidogrel as an alternative to warfarin in patients with a $\mathrm{CHADS}_{2}$ score of $1 .{ }^{33}$ The American College of Chest Physicians recommends use of warfarin or acetylsalicylic acid combined with clopidogrel for patients with a CHADS 2 score $\geq 2 .{ }^{33}$ The physician's choice of acetylsalicylic acid in patients at low or moderate risk must take into account patient preference, the likely bleeding risk if warfarin is the concurrent anticoagulant, and the availability of access to high-quality monitoring of anticoagulation. ${ }^{33}$ For many patients considered to be at high or moderate risk, adjusted-dose warfarin to a target INR in the 2.0-3.0 range is recommended. ${ }^{32,33}$ For high-risk patients who prefer not to be treated with warfarin or for whom warfarin is unsuitable, the ACC/AHA/ASA guidelines suggest that dual antiplatelet therapy with clopidogrel and acetylsalicylic acid is reasonable. ${ }^{32}$ However, the risk of hemorrhage is not lower with dual antiplatelet therapy than with warfarin, and dual antiplatelet therapy provides greater protection against stroke than acetylsalicylic acid alone at the price of a higher risk of major bleeding. ${ }^{32}$

Prevention of major vascular events with acetylsalicylic acid alone and with acetylsalicylic acid plus clopidogrel were compared in ACTIVE A (the Atrial Fibrillation Clopidogrel Trial with Irbesartan for Prevention of Vascular Events). ${ }^{34}$ Patients with AF ( $\mathrm{n}=7554$, mean age 71 years) who were not candidates for warfarin therapy were randomized to treatment with acetylsalicylic acid plus either clopidogrel $(n=3772)$ or placebo $(n=3782)$. Patients enrolled between June 2003 and May 2006 were followed until the conclusion of the study in November 2008. Median duration of follow-up was 3.6 years. The primary endpoint for the study was any major vascular event (stroke, non-central nervous system systemic embolism, myocardial infarction, or death from vascular causes) and the most important secondary outcome was stroke. The primary endpoint occurred in 832 patients receiving clopidogrel $(6.8 \%$ per year) compared with 924 patients on placebo (7.6\% per year; relative risk $0.89,95 \% \mathrm{CI} 0.81-0.98, P=0.01)$. The reduction in risk of major vascular events among clopidogrel-treated patients was mainly the result of a lower incidence of stroke, which occurred in 296 patients on clopidogrel compared with 408 on placebo (relative risk $0.72,95 \%$ CI $0.62-0.83$; $P<0.001$ ). Major bleeding occurred in 251 patients in the clopidogrel group $(2.0 \%$ per year) versus 162 patients in the placebo group (1.3\% per year, relative risk 1.57 ; $95 \%$ CI $1.29-1.92$; $P<0.001)$. Clopidogrel-treated patients experienced an excess of 83 major bleeding episodes not related to stroke, including 62 episodes classified as severe and an excess of 13 fatal episodes. When major vascular episodes and hemorrhage were considered together, there was no significant difference in the overall event rate between the group treated with acetylsalicylic acid alone and the group treated with acetylsalicylic acid plus clopidogrel (968 versus 996 events; relative risk $0.97,95 \% \mathrm{CI} 0.89-1.06 ; P=0.54) .^{34}$

The 2010 European Society of Cardiology guidelines largely dispensed with categorizations of high, medium, and low risk. Instead, they encouraged physicians to view risk as a continuum and advocated an approach to clinical assessment and management based on the cumulative presence or absence of risk factors. ${ }^{35}$ This risk factor-based approach corresponds to the $\mathrm{CHA}_{2} \mathrm{DS}_{2}$-Vasc scoring system previously described. The European Society of Cardiology guidelines were updated, according to the results of several largescale clinical trials, shortly before the approval of new oral anticoagulants. For patients with a $\mathrm{CHA}_{2} \mathrm{DS}_{2}$-Vasc score of 0 and no risk factors other than AF, they recommend either acetylsalicylic acid $72-325 \mathrm{mg} /$ day or no antithrombotic therapy, with a preference for the latter. The authors of the guidelines considered that for this group, data on acetylsalicylic acid were insufficient to show benefit, whereas the potential for adverse effects, especially bleeding, was known. For patients with one clinically relevant but "nonmajor" risk factor, they advised either an oral anticoagulant such as a vitamin $\mathrm{K}$ antagonist adjusted to a target INR of 2.0-3.0, or acetylsalicylic acid $72-325 \mathrm{mg} /$ day, but preferably the former. For patients with one major risk factor and at least two clinically relevant, nonmajor risk factors, they recommended an oral anticoagulant (target INR 2.0-3.0). Anticipating approval of the new oral anticoagulants, the 2010 European Society of Cardiology guidelines advised that dabigatran etexilate may 
be considered as an alternative to adjusted-dose vitamin $\mathrm{K}$ antagonist therapy. The authors of the guidelines also urged use of the HAS-BLED score, described earlier, in assessing bleeding risk, selecting medication, and monitoring anticoagulant therapy. ${ }^{35}$ Revised European Society of Cardiology guidelines were published in late August 2012.

\section{New oral anticoagulation therapies}

More than a decade ago, leading investigators in antithrombotic therapy emphasized the need for development of orally active anticoagulants with at least comparable efficacy, and superior safety, to the standard coumarin derivatives in long-term stroke risk reduction therapy. ${ }^{25,29}$ Targets for anticoagulant intervention in the coagulation cascade are shown schematically in Figure $1 .{ }^{36}$ A number of parenterally administered agents have been introduced to practice in recent years. However, the need for innovative oral anticoagulant strategies has been met by the direct thrombin inhibitor, dabigatran etexilate, and the factor Xa inhibitor, rivaroxaban. Both of these agents are approved by the FDA for reducing the risk of stroke and systemic embolism in patients with nonvalvular AF; rivaroxaban is also indicated for the prophylaxis of deep vein thrombosis, which may lead to pulmonary embolism in patients undergoing knee or hip replacement surgery. ${ }^{37,38}$ A second factor Xa inhibitor, apixaban, has recently been approved by the FDA.

\section{Direct thrombin inhibitors}

Direct thrombin inhibitors have a well defined mechanism of action. Thrombin, central to the clotting process, converts

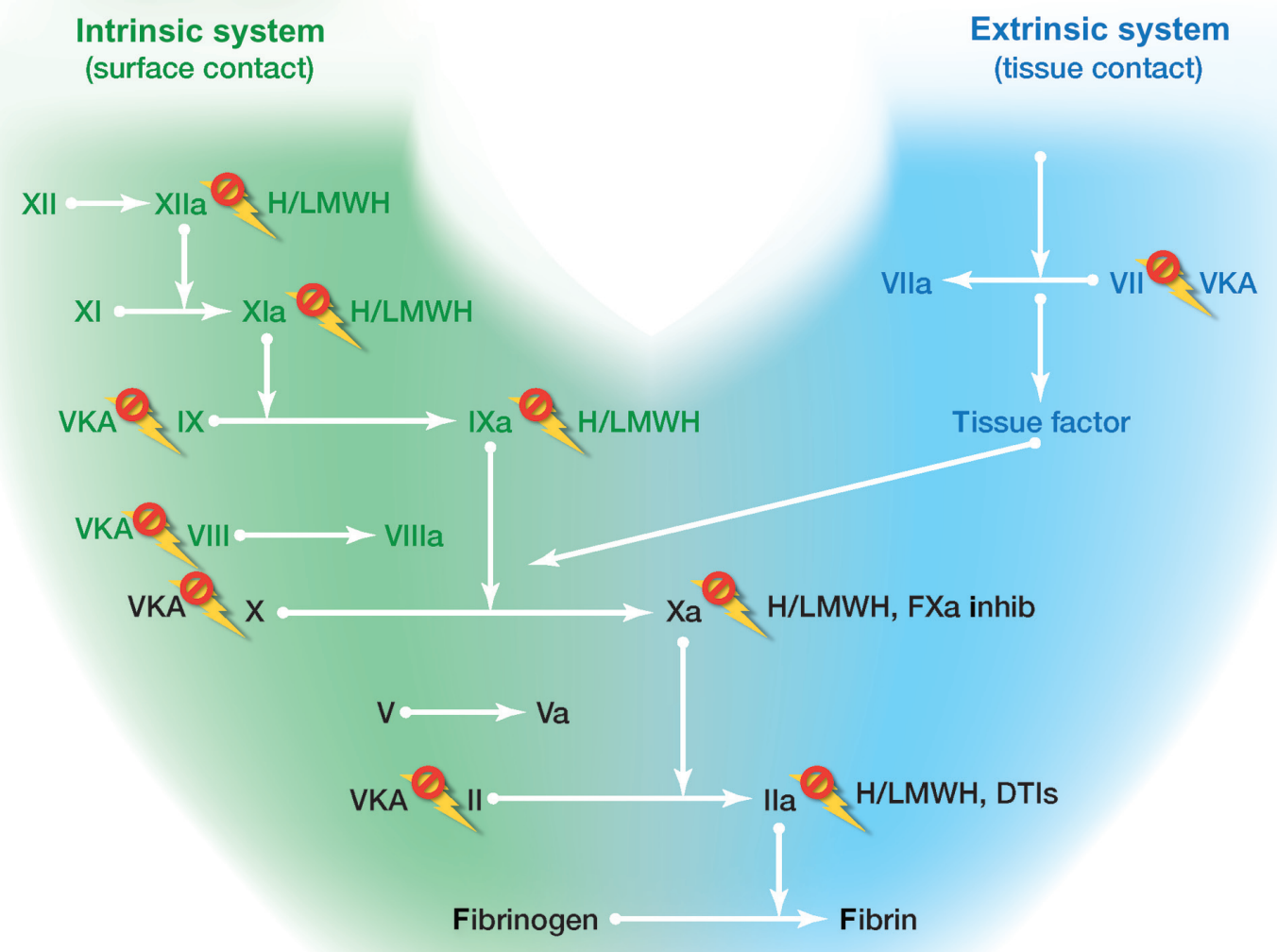

Figure I Coagulation cascade: targets for antithrombotic intervention.

Notes: Coagulation is initiated when the injured endothelium releases tissue factor, which activates the extrinsic pathway. Amplification, key to the coagulation cascade, is triggered by intrinsic coagulation pathway factors that are activated by tissue factor-Vlla in a positive feedback loop. The extrinsic and intrinsic pathways converge at the level of factor $\mathrm{X}$ activation, which activates the final common pathway. In turn, factor Xa combines with factor Va, calcium, and platelet phospholipids to form prothrombinase complex, which activates prothrombin to thrombin, the final enzyme in the process that converts fibrinogen to fibrin. ${ }^{36}$ Warfarin inhibits synthesis of the active forms of four vitamin K-dependent procoagulant proteins, ie, factors II (prothrombin), VII, IX, and X, as well as two anticoagulant proteins, C and S. LMWHs are derived from unfractionated heparin by depolymerization, which forms fragments approximately one third the size of unfractionated heparin. The smaller LMWH fragments still contain the parent compound's essential antithrombin III-binding pentasaccharide sequence and thus can catalyze factor Xa inactivation. Precluded by their smaller fragment chain length from simultaneously bridging antithrombin III and thrombin, which is required for thrombin lla inactivation, most LMWH agents demonstrate high anti-Xa activity and minimal anti-Ila activity. Factor Xa inhibitors are synthetic analogs of the pentasaccharide sequence that binds with high affinity to antithrombin III. These agents catalyze inactivation of factor $\mathrm{Xa}$, thus decreasing thrombin generation. DTIs bind directly to the active site of thrombin and block interaction with its substrate, fibrinogen. In contrast with LMWH, DTIs inactivate clot-bound thrombin, which promotes thrombus growth and circulating thrombin.

Abbreviations: $\mathrm{H}$, heparin; LMWH, low-molecular-weight heparin; VKA, vitamin K antagonist; FXa Inhib, factor Xa inhibitor; DTI, direct thrombin inhibitor. 
soluble fibrinogen to fibrin and activates other clotting factors, which, in turn, generate more thrombin and stimulate platelets. Thrombin also activates factor XIII, which facilitates bonding among fibrin molecules and stabilizes the clot. ${ }^{36}$ Direct thrombin inhibitors prevent thrombin activity by occupying catalytic binding sites, fibrinogen binding sites, or both; inhibit thrombin in both the inactive fluid phase and the stabilized fibrin-bound state; and inhibit surface-bound thrombin, with the effect of attenuating thrombus growth. ${ }^{36}$

Several direct thrombin inhibitors (hirudin, bivalirudin, argatroban) have been in use for a number of years but must be administered parenterally. ${ }^{39}$ In late-stage clinical trials, ximelagatran, the first oral direct thrombin inhibitor, was equivalent to warfarin for stroke prevention in $\mathrm{AF}$ patients and was subsequently marketed in Europe for the prevention of primary venous thromboembolism. ${ }^{40}$ However, postmarketing reports of hepatotoxicity resulted in withdrawal of this agent from the market.

The new oral direct thrombin inhibitor, dabigatran etexilate, in contrast with warfarin, has a rapid onset of anticoagulant effect, predictable pharmacodynamics, and few drug-drug interactions. Dabigatran etexilate is a prodrug that is rapidly converted into its active form, dabigatran, by esterases. ${ }^{41}$ The 2011 focused update to the $2006 \mathrm{ACC} /$ AHA/ESC guidelines recommends dabigatran etexilate as a useful alternative to warfarin to reduce the risk of stroke and systemic thromboembolism in patients with AF and at least one additional risk factor for stroke and systemic thromboembolism. ${ }^{32}$ Contraindications include active pathological bleeding or a history of a serious hypersensitivity reaction to dabigatran. ${ }^{37}$ Dabigatran etexilate is approved for use without routine coagulation monitoring. ${ }^{37,41}$

The 2011 update to the ACC/AHA/ESC guidelines is based on the results of the RE-LY (Randomized Evaluation of Long-term anticoagulant therapY) study. ${ }^{42,43}$ In this trial, 18,113 patients with nonvalvular AF and at least one additional risk factor for stroke were randomized either to blinded treatment with fixed-dose oral dabigatran (110 mg or $150 \mathrm{mg}$ twice daily) or to adjusted-dose warfarin (warfarin treatment was well controlled; mean time in therapeutic range was 64\%). Patients were followed for a median of 2 years for the composite endpoint of stroke and systemic thromboembolism. At study endpoint, the rate of stroke and systemic thromboembolism was $1.71 \%$ per year among patients randomized to warfarin versus $1.54 \%$ per year in patients randomized to dabigatran $110 \mathrm{mg}$ twice daily (relative risk for dabigatran $110 \mathrm{mg}, 0.90 ; 95 \%$ CI $0.74-1.10$; $P<0.001$ for noninferiority) and $1.11 \%$ per year in patients who received dabigatran $150 \mathrm{mg}$ twice daily (relative risk for dabigatran $150 \mathrm{mg}, 0.65 ; 95 \%$ CI $0.52-0.81 ; P<0.001$ for superiority). The rate of major bleeding was $3.57 \%$ per year with warfarin versus $2.87 \%$ per year with dabigatran $110 \mathrm{mg}(P=0.003)$ and $3.32 \%$ per year in the dabigatran $150 \mathrm{mg}$ group $(P=0.32)$. The rate of hemorrhagic stroke was significantly lower among patients who received dabigatran (110 mg, $0.12 \% ; 150 \mathrm{mg}, 0.10 \%$ ) than in those who received warfarin $(0.38 \% ; P<0.001$ for both comparisons $) .{ }^{42}$ There were significant reductions in intracranial hemorrhage, which occurred at annual rates of $0.23 \%$ and $0.32 \%$, respectively, for dabigatran $110 \mathrm{mg}$ bid and dabigatran $150 \mathrm{mg}$ bid, compared with $0.76 \%$ for warfarin $(P<0.0001) .{ }^{44}$ The mortality rate was $4.13 \%$ per year with warfarin versus $3.75 \%$ per year with dabigatran $110 \mathrm{mg}(P=0.13)$ and $3.64 \%$ per year with dabigatran $150 \mathrm{mg}(P=0.051){ }^{42,43}$ Using insurance claims and administrative data from the Mini-Sentinel pilot of the Sentinel Initiative, the FDA compared the actual rates of gastrointestinal bleeding for new users of dabigatran versus new users of warfarin during the period from 19 October 2010 (dabigatran's FDA approval date) through 31 December $2011 .^{45}$ The incidence rate of gastrointestinal bleeding events per 100,000 days at risk was 1.6-2.2 times higher for new warfarin users than for new dabigatran users, consistent with observations from the RE-LY trial. ${ }^{45}$

Overall, the results indicated that in patients with $\mathrm{AF}$, dabigatran at the dose of $150 \mathrm{mg}$ twice daily was superior to warfarin in preventing stroke and systemic thromboembolism, caused significantly less intracranial bleeding and comparable extracranial bleeding, and was associated with less cardiovascular mortality. ${ }^{42-45}$ The FDA approved dabigatran etexilate $150 \mathrm{mg}$ twice daily to reduce the risk of stroke and systemic thromboembolism in patients with nonvalvular $\mathrm{AF}$ and normal renal function or moderate renal impairment (creatinine clearance $>30 \mathrm{~mL}$ per minute). ${ }^{37}$ Dabigatran etexilate $75 \mathrm{mg}$ twice daily is recommended for patients with a creatinine clearance of $15-30 \mathrm{~mL}$ per minute. ${ }^{37}$

Results of a meta-analysis of seven noninferiority trials indicated an increase in the risk of myocardial infarction or acute coronary syndrome with dabigatran therapy compared with controls including warfarin. ${ }^{46}$ Although the increase in relative risk compared with warfarin was $33 \%$, the absolute risk increase was very small, at $0.27 \% .{ }^{46}$ Warfarin is known to prevent myocardial infarction, as is acetylsalicylic acid, which was allowed concurrently in all the trials. The authors suggested that dabigatran may not directly increase the risk of myocardial infarction, but may lack the beneficial effects of warfarin in prevention of myocardial infarction. ${ }^{46}$ 
The reduction in ischemic stroke risk with dabigatran therapy appears to confer a favorable benefit to risk balance. However, selection guidelines should be closely followed, especially among patients at high risk for myocardial infarction or acute coronary syndrome. ${ }^{46}$

\section{Factor $\mathrm{Xa}$ inhibitors}

A double-blind Phase III trial, ROCKET-AF (Rivaroxaban Once-daily oral direct factor Xa inhibition Compared with vitamin $\mathrm{K}$ antagonism for the prevention of stroke and Embolism Trial in Atrial Fibrillation), compared the oral direct factor Xa inhibitor rivaroxaban at a dose of $20 \mathrm{mg} /$ day with dose-adjusted warfarin for stroke prevention in patients with nonvalvular AF. For warfarin-treated patients, mean time in therapeutic range was $55 \% .{ }^{47}$ The composite primary efficacy and safety endpoints were all-cause stroke and noncentral nervous system systemic embolism, and major and clinically relevant nonmajor bleeding events, respectively. ${ }^{47}$ In the primary analysis, the primary endpoint occurred in 188 rivaroxaban-treated patients (1.7\% per year) compared with 241 warfarin-treated patients $(2.2 \%$ per year; $P<0.001$ for noninferiority). ${ }^{47}$ In the intention-to-treat analysis, the primary endpoint occurred in 269 rivaroxaban-treated patients compared with 306 warfarin-treated patients $(2.1 \%$ per year and $2.4 \%$ per year, respectively; $P<0.001$ for noninferiority, $P=0.12$ for superiority). ${ }^{47}$ Major and nonmajor clinically relevant bleeding occurred in 1475 patients in the rivaroxaban group compared with 1449 in the warfarin group (14.9\% per year and $14.5 \%$ per year, respectively; $P=0.44)$. There were significant reductions in intracranial hemorrhage $(0.5 \%$ versus $0.7 \%, P=0.02)$ and fatal bleeding $(0.2 \%$ versus $0.5 \%$, $P=0.003)$ in the rivaroxaban group. ${ }^{47}$

In a randomized comparison, 1584 patients received oral rivaroxaban $10 \mathrm{mg}$ once daily and 1564 received subcutaneous enoxaparin $30 \mathrm{mg}$ every 12 hours. ${ }^{48}$ The primary efficacy outcome was the composite of deep vein thrombosis, nonfatal pulmonary embolism, or all-cause mortality $\leq 17$ days after knee arthroplasty. The primary efficacy outcome occurred in $6.9 \%$ of rivaroxaban-treated patients and $10.1 \%$ of those treated with enoxaparin, for an absolute risk reduction of $3.19 \%(P=0.0118)$. Major bleeding was observed in $0.7 \%$ of rivaroxaban-treated patients compared with $0.3 \%$ of enoxaparin-treated patients $(P=0.1096) .^{48}$

In a further comparison study, patients scheduled for elective total hip arthroplasty were randomly assigned to treatment with oral rivaroxaban $10 \mathrm{mg}$ once daily $(\mathrm{n}=1252)$ or subcutaneous enoxaparin $40 \mathrm{mg}$ once daily $(\mathrm{n}=1257) .{ }^{49}$ The primary efficacy outcome was the composite of deep vein thrombosis, nonfatal pulmonary embolism, or allcause mortality $\leq 30-42$ days after surgery. In the modified intention-to-treat analysis, the primary outcome occurred in $2.0 \%$ of rivaroxaban-treated patients compared with $9.3 \%$ of enoxaparin-treated patients, for an absolute risk reduction of $7.3 \%(P<0.0001)$. The incidence of any bleeding on treatment did not differ significantly between the groups $(P=0.25){ }^{49}$

Apixaban, another factor Xa inhibitor in development to reduce the risk of stroke in AF, is currently under FDA review. The AVERROES (Apixaban VERsus acetylsalicylic acid to pRevent strOkES) study, conducted in patients in whom vitamin $\mathrm{K}$ antagonist therapy failed or was deemed unsuitable, evaluated apixaban as a substitute for acetylsalicylic acid in patients with AF. ${ }^{50}$ The study was halted early due to preliminary findings of a risk reduction of more than $50 \%$ with apixaban versus acetylsalicylic acid, with no increase in major bleeding or liver toxicity. ${ }^{50}$ The ARISTOTLE (Apixaban for the pReventIon of Stroke in subjecTs with aTrial fibriLLation) study compared the efficacy and safety of apixaban $5 \mathrm{mg}$ twice daily $(\mathrm{n}=9120)$ and warfarin to an INR of 2.0-3.0 $(n=9081)$ for stroke prevention in $A F^{51}$ A predefined group of patients $>80$ years, with low body weight and/or impaired renal function received half the test dose, ie, $2.5 \mathrm{mg}$ twice daily. In this trial, which was designed to test for noninferiority, the primary outcome was ischemic or hemorrhagic stroke or systemic embolism, and the secondary objectives were to test for superiority with respect to the primary outcome and rates of major bleeding and all-cause mortality. Over a median follow-up of 1.8 years, the primary outcome occurred at a rate of $1.27 \%$ per year in the apixaban group compared with $3.09 \%$ per year in the warfarin group $(P<0.001)$, and the rates of all-cause mortality were $3.52 \%$ and $3.94 \%$, respectively. Hemorrhagic stroke occurred at a rate of $0.24 \%$ per year in the apixaban group compared with $0.47 \%$ per year in the warfarin group $(P<0.0001)$, and the rate of ischemic/uncertain stroke type was $0.95 \%$ per year in the apixaban group and $1.05 \%$ per year in the warfarin group $(P=0.42) .{ }^{51}$ The results indicated that, in patients with atrial fibrillation, apixaban was superior to warfarin in preventing stroke and systemic thromboembolism, caused less bleeding, and was associated with a lower mortality rate. ${ }^{51}$ Other factor $\mathrm{Xa}$ inhibitors are in various stages of development.

\section{Management of new anticoagulants}

To date, relatively limited evidence is available to inform decisions around management of new anticoagulants. However, expert opinion recommends that bleeding events 
should be risk-stratified. ${ }^{52}$ Minor bleeding, such as epistaxis or menorrhagia, can be managed with withdrawal of the agent for one or more days, allowing for interventions as indicated. Moderate bleeding can be managed with drug withdrawal, clinical monitoring, symptomatic treatment, mechanical compression or surgical intervention, fluid replacement, and hemodynamic support and/or transfusion of blood products. Major bleeding should be managed with drug withdrawal, monitoring, hospital admission if required for stabilization, and administration of coagulation factors in case of lifethreatening bleeding. ${ }^{52}$

\section{Conclusion}

Warfarin has a long history of attenuating the risk of stroke in patients with AF; however, its limitations lead to both overcoagulation and undercoagulation and, in some cases, failure to use anticoagulation at all. Alternative anticoagulant modalities, such as direct thrombin inhibitors and factor Xa inhibitors, have the potential to improve outcomes in patients with $\mathrm{AF}$ and reduce the burdens associated with coagulation monitoring and dose adjustment. Dabigatran etexilate demonstrated equivalent or superior efficacy and safety to warfarin without the need for routine coagulation monitoring during clinical trials and was the first FDA-approved alternative to vitamin $\mathrm{K}$ antagonist therapy to reduce the risk of stroke in patients with nonvalvular AF. The factor Xa inhibitor rivaroxaban is also FDA-approved for this indication, and apixaban is now available. New oral anticoagulants appear to have a pivotal role in reducing the risk of stroke for patients with AF.

\section{Disclosure}

The author acknowledges the writing and editorial assistance of UBC-Envision Group, the services of which were funded by Boehringer Ingelheim Pharmaceuticals Inc. The author meets criteria for authorship as recommended by the International Committee of Medical Journal Editors (ICMJE), was fully responsible for all content and editorial decisions, and was involved in all stages of manuscript development. The author received no compensation related to the development of the manuscript. Otherwise, the author reports no conflicts of interest in this work.

\section{References}

1. Falk RH. Atrial fibrillation. N Engl J Med. 2001;344:1067-1078.

2. Watson T, Shantsila E, Lip GYH. Mechanisms of thrombogenesis in atrial fibrillation: Virchow's triad revisited. Lancet. 2009;373:155-166.

3. Romero JR, Morris J, Pikula A. Stroke prevention: modifying risk factors. Ther Adv Cardiovasc Dis. 2008;2:287-303.
4. Go AS, Hylek EM, Phillips KA, et al. Prevalence of diagnosed atrial fibrillation in adults: national implications for rhythm management and stroke prevention: the AnTicoagulation and Risk Factors in Atrial Fibrillation (ATRIA) Study. JAMA. 2001;285:2370-2375.

5. Lloyd-Jones DM, Wang TJ, Leip EP, et al. Lifetime risk for development of atrial fibrillation: the Framingham Heart Study. Circulation. 2004;110:1042-1046.

6. Feinberg WM, Blackshear JL, Laupacis A, Kronmal R, Hart RG. Prevalence, age distribution, and gender of patients with atrial fibrillation. Analysis and implications. Arch Intern Med. 1995;155:469-473.

7. Roger VL, Go AS, Lloyd-Jones DM, et al. Heart disease and stroke statistics - 2012 update: a report from the American Heart Association. Circulation. 2012;125:e2-e220.

8. Heidenreich PA, Trogdon JG, Khavjou OA, et al. Forecasting the future of cardiovascular disease in the United States: a policy statement from the American Heart Association. Circulation. 2011;123:933-944.

9. Mahan CE, Holdsworth MT, Welch SM, Borrego M, Spyropoulos AC. Deep-vein thrombosis: a United States cost model for a preventable and costly adverse event. Thromb Haemost. 2011;106:405-415.

10. Wolf PA, Mitchell JB, Baker CS, Kannel WB, D’Agostino RB. Impact of atrial fibrillation on mortality, stroke, and medical costs. Arch Intern Med. 1998;158:229-234.

11. Fang MC, Singer DE, Chang Y, et al. Gender differences in the risk of ischemic stroke and peripheral embolism in atrial fibrillation: the AnTicoagulation and Risk factors In Atrial fibrillation (ATRIA) study. Circulation. 2005;112:1687-1691.

12. Fuster V, Rydén LE, Cannom DS, et al. ACC/AHA/ESC 2006 Guidelines for the Management of Patients with Atrial Fibrillation: a report of the American College of Cardiology/American Heart Association Task Force on Practice Guidelines and the European Society of Cardiology Committee for Practice Guidelines (Writing Committee to Revise the 2001 Guidelines for the Management of Patients With Atrial Fibrillation): developed in collaboration with the European Heart Rhythm Association and the Heart Rhythm Society. Circulation. 2006;114:e257-e354.

13. Lip GY, Nieuwlaat R, Pisters R, Lane DA, Crijns HJ. Refining clinical risk stratification for predicting stroke and thromboembolism in atrial fibrillation using a novel risk factor-based approach: the Euro heart survey on atrial fibrillation. Chest. 2010;137:263-272.

14. Wang TJ, Massaro J, Levy D, et al. A risk score for predicting stroke or death in individuals with new-onset atrial fibrillation in the community. The Framingham Heart Study. JAMA. 2003;290:1049-1056.

15. Lip GY. Implications of the CHA(2)DS(2)-VASc and HAS-BLED scores for thromboprophylaxis in atrial fibrillation. $\mathrm{Am} \mathrm{J} \mathrm{Med.}$ 2011;124:111-114.

16. Gage BF, Yan Y, Milligan PE, et al. Clinical classification schemes for predicting hemorrhage: Results from the National Registry of Atrial Fibrillation (NRAF). Am Heart J. 2006;151:713-719.

17. Hyers TM, Agnelli G, Hull RD, et al. Antithrombotic therapy for venous thromboembolic disease. Chest. 2001;119:176S-193S.

18. De Caterina R. The current role of anticoagulants in cardiovascular medicine. J Cardiovasc Med. 2009;10:595-604.

19. Hart RG, Pearce LA, Aguilar MI. Meta-analysis: antithrombotic therapy to prevent stroke in patients who have nonvalvular atrial fibrillation. Ann Intern Med. 2007;146:857-867.

20. Flockhart DA, O'Kane D, Williams MS, et al. Pharmacogenetic testing of CYP2C9 and VKORC1 alleles for warfarin. Genet Med. 2008;10: $139-150$.

21. Gage BF, Fihn SD, White RH. Management and dosing of warfarin therapy. Am J Med. 2000;109:481-488.

22. Brass LM, Krumholz HM, Scinto JM, Radford M. Warfarin use among patients with atrial fibrillation. Stroke. 1997;28:2382-2389.

23. Albers GW, Yim JM, Belew KM, et al. Status of antithrombotic therapy for patients with atrial fibrillation in university hospitals. Arch Intern Med. 1996;156:2311-2316.

24. Hylek EM, Go AS, Chang Y, Henault LE, Selby JV, Singer DE. Effect of intensity of oral anticoagulation on stroke severity and mortality in atrial fibrillation. N Engl J Med. 2003;349:1019-1026. 
25. Hylek EM, Skates SJ, Sheehan MA, Singer DE. An analysis of the lowest effective intensity of prophylactic anticoagulation for patients with nonrheumatic atrial fibrillation. N Engl J Med. 1996;335:540-546.

26. Darkow T, Vanderplas AM, Lew KH, Kim J, Hauch O. Treatment patterns and real-world effectiveness of warfarin in nonvalvular atrial fibrillation within a managed care system. Curr Med Res Opin. 2005;21: 1583-1594.

27. McCormick D, Gurwitz JH, Goldberg RJ, et al. Prevalence and quality of warfarin use for patients with atrial fibrillation in the long-term care setting. Arch Intern Med. 2001;161:2458-2463.

28. Jones M, McEwan P, Morgan CL, Peters JR, Goodfellow J, Currie CJ. Evaluation of the pattern of treatment, level of anticoagulation control, and outcome of treatment with warfarin in patients with non-valvular atrial fibrillation: a record linkage study in a large British population. Heart. 2005;91:472-477.

29. Ansell JE, Weitz JI, Comerota AJ. Advances in therapy and the management of antithrombotic drugs for venous thromboembolism. Hematology Am Soc Hematol Educ Program. 2000:266-284.

30. Chambers S, Chadda S, Plumb JM. How much does international normalized ratio monitoring cost during oral anticoagulation with a vitamin K antagonist? A systematic review. Int J Lab Hematol. 2010;32: 427-442.

31. Mant J, Hobbs FD, Fletcher K, et al. Warfarin versus aspirin for stroke prevention in an elderly community population with atrial fibrillation (the Birmingham Atrial Fibrillation Treatment of the Aged Study, BAFTA): a randomised controlled trial. Lancet. 2007;370: 493-503.

32. Wann LS, Curtis AB, January CT, et al. 2011 ACCF/AHA/HRS focused update on the management of patients with atrial fibrillation (updating the 2006 Guideline): a report of the American College of Cardiology Foundation/American Heart Association Task Force on Practice Guidelines. J Am Coll Cardiol. 2011;57:223-242.

33. Guyatt GH, Akl EA, Crowther M, Gutterman DD, Schuünemann HJ. Executive summary: Antithrombotic Therapy and Prevention of Thrombosis, 9th ed: American College of Chest Physicians Evidence-Based Clinical Practice Guidelines. Chest. 2012;141:7S-47S.

34. Connolly SJ, Pogue J, Hart RG, et al. Effect of clopidogrel added to aspirin in patients with atrial fibrillation. $N$ Engl $J$ Med. 2009;360: 2066-2078.

35. Camm AJ, Kirchhof P, Lip GY, et al; for the Task Force for the Management of Atrial Fibrillation of the European Society of Cardiology (ESC). Guidelines for the management of atrial fibrillation. Eur Heart J. 2010;31:2369-2429.

36. Di Nisio M, Middeldorp S, Buller HR. Direct thrombin inhibitors. N Engl J Med. 2005;353:1028-1040.

37. Pradaxa ${ }^{\circledR}$ (dabigatran etexilate) product information. Ridgefield, CT: Boehringer-Ingelheim Pharmaceuticals Inc; 2012.
38. Xarelto ${ }^{\circledR}$ (rivaroxaban) product information. Titusville, NJ: Janssen Pharmaceuticals Inc; 2011.

39. Hirsh J, Bauer KA, Donati MB, et al. Parenteral anticoagulants: American College of Chest Physicians evidence-based clinical practice guidelines (8th edition). Chest. 2008;133(Suppl 6):141S-159S

40. Albers GW, Diener HC, Frison L, et al. Ximelagatran vs warfarin for stroke prevention in patients with nonvalvular atrial fibrillation: a randomized trial. JAMA. 2005;293:690-698.

41. Stangier J, Rathgen K, Stähle H, Gansser D, Roth W. The pharmacokinetics, pharmacodynamics and tolerability of dabigatran etexilate, a new oral direct thrombin inhibitor, in healthy male subjects. Br J Clin Pharmacol. 2007;64:292-303.

42. Connolly SJ, Ezekowitz MD, Yusuf S, et al. Dabigatran versus warfarin in patients with atrial fibrillation. $N$ Engl J Med. 2009;361:1139-1151.

43. Connolly SJ, Ezekowitz MD, Yusuf S, Reilly PA, Wallentin L. Newly identified events in the RE-LY trial. N Engl J Med. 2010;363: 1875-1876.

44. Hart RG, Diener HC, Yang S, et al. Intracranial hemorrhage in atrial fibrillation patients during anticoagulation with warfarin or dabigatran. The RE-LY Trial. Stroke. 2012;43:1511-1517.

45. FDA Drug Safety Communication. Update on the risk for serious bleeding events with the anticoagulant Pradaxa. Available from: http://www. fda.gov/Drugs/DrugSafety/ucm326580.htm. Accessed November 26, 2012

46. Uchino K, Hernandez AV. Dabigatran association with higher risk of acute coronary events. Meta-analysis of noninferiority randomized controlled trials. Arch Intern Med. 2012;172:397-402.

47. Patel MR, Mahaffey KW, Garg J, et al; for the ROCKET-AF Investigators. Rivaroxaban versus warfarin in nonvalvular atrial fibrillation. N Engl J Med. 2011;365:883-891.

48. Turpie AG, Lassen MR, Davidson BL, et al. Rivaroxaban versus enoxaparin for thromboprophylaxis after total knee arthroplasty (RECORD4): a randomised trial. Lancet. 2009;373:1673-1680.

49. Kakkar AK, Brenner B, Dahl OE, et al. Extended duration rivaroxaban versus short-term enoxaparin for the prevention of venous thromboembolism after total hip arthroplasty: a double-blind, randomised controlled trial. Lancet. 2008;372:31-39.

50. Eikelboom JW, O'Donnell M, Yusuf S, et al. Rationale and design of AVERROES: apixaban versus acetylsalicylic acid to prevent stroke in atrial fibrillation patients who have failed or are unsuitable for vitamin $\mathrm{K}$ antagonist treatment. Am Heart J. 2010;159:348-353.

51. Granger CB, Alexander JH, McMurray JJ, et al. Apixaban versus warfarin in patients with atrial fibrillation. $N$ Engl J Med. 2011;365: 981-992.

52. Schulman S, Crowther MA. How I treat with anticoagulants in 2012: new and old anticoagulants, and when and how to switch. Blood. 2012;119:3016-3023.
Clinical Interventions in Aging

\section{Publish your work in this journal}

Clinical Interventions in Aging is an international, peer-reviewed journal focusing on evidence-based reports on the value or lack thereof of treatments intended to prevent or delay the onset of maladaptive correlates of aging in human beings. This journal is indexed on PubMed Central, MedLine, the American Chemical Society's 'Chemical Abstracts Ser-

\section{Dovepress}

vice' (CAS), Scopus and the Elsevier Bibliographic databases. The manuscript management system is completely online and includes a very quick and fair peer-review system, which is all easy to use. Visit http://www.dovepress.com/testimonials.php to read real quotes from published authors. 